\title{
Validation of a Lean Smart Maintenance Maturity Model
}

\author{
Hans Thomas Maier*, Oliver Schmiedbauer, Hubert Biedermann
}

\begin{abstract}
Rising complexity in industrial asset and maintenance management due to more volatile business environments and megatrends like Industry 4.0 has led to the need for a new perspective on these management domains. The Lean Smart Maintenance (LSM) philosophy, which focuses on both the efficient (lean) and the learning (smart) organization was introduced during the past few years, and a corresponding maturity model (MM) has been developed to guide organizations on their way to asset and maintenance excellence. This paper discusses use cases, in which the usability and the generic aspect of the LSM MM are validated by using data from three different asset management assessment projects in organizations with different types of production. Research results show that the LSM MM can be used as a basis for management system improvement, independent of production types such as one-of-a-kind industry, mass production and continuous production.
\end{abstract}

Keywords: asset management; capability maturity model; digitalization; digitization; Industry 4.0; Lean Smart Maintenance (LSM); maintenance; smart factory

\section{INTRODUCTION}

The volatile market conditions are exerting more and more pressure on companies and the management level, which needs to increase productivity, save resources and improve organizational processes to remain competitive. With increasing automation and digitalization, the focus is placed on asset and maintenance management as an even more significant value-adding function. As a result of this need for management tools to facilitate digitization and digitalization, a variety of maturity models around the topic of Industry 4.0 (I4.0) have been developed and published [16]. However, maturity models (MM) that focus on asset and maintenance management are still rare. Therefore, the authors of this paper proposed in a previous publication [7] a generic maturity model which takes a holistic approach on asset management, maintenance processes and organization, and finally I4.0 aspects. Further research questions arose from this previous publication and this paper focuses on answering one of these questions: Is the new LSM MM generically applicable for different production types? In this context, the applicability of the LSM MM is validated with project data of previous reorganization projects with differing production types. The paper is structured in a way to create a comprehensive understanding of the authors' approach to transforming the gathered information from existing LSM projects into the LSM MM. In section 2, a summary of the theory of asset and maintenance management, as well as the associated I4.0 aspects, is given. It is followed by an introduction into the LSM MM, which was first published in 2020. Next, the methodological approach is explained in section 3 . In section 4 , the project data around the business cases which were used to prove the generality of the LSM I4.0 model is presented. Section 5 takes a look at the maturities of the companies based on the new LSM MM. Finally, a critical reflection of the results is performed, and further steps of investigation and development are presented.

\section{THEORETICAL BACKGROUND}

This section takes a look at the theoretical background around the terms Industry 4.0, asset and maintenance management and finally, the Lean Smart Maintenance maturity model.

\subsection{Industry 4.0}

In 2011, the term 'Industry 4.0' (or Industrie 4.0) was introduced by the German government, and thus laid the cornerstones of the current industrial orientation, not only in Europe, but also in the rest of the world. The concept of I4.0 is mainly known in Europe, but 'Industrial Internet' [8] 'Smart Industry' or 'Smart Manufacturing' [9-12] are only a few examples of comparable industry concepts. Industries from steel to automobile manufacturing - are inspired by the concepts of collaborating machines and factories, connected suppliers and manufacturer, and I4.0 enablers, such as the Internet of Things (IoT), cloud computing, Internet of Everything (IoE), additive manufacturing, hyper-automation, etc. $[13,14]$. The deployment of IoE is the final step in connecting not only machines and server with each other, but also in creating an interconnection between processes, data, things and people, resulting in generating more value out of existing configurations [15]. This interconnection is only possible by the increase of processor performance, data storage availability and the increasing data transfer capacity. With the growing number of sensors and connections, the amount of data to be processed increases enormously. [16] This available data enables optimization of processes, reduces costs, increases efficiency, and enhances interoperability between different organizational units [17].

\subsection{Maintenance \& Asset Management}

According to DIN EN 13306, "maintenance is the combination of all technical, administrative and managerial actions during the life cycle of an item intended to retain it in or restore it to, a state in which it can perform the required function" [18]. Asset management (AM) takes a more holistic 
approach [19], as it "involves the balancing of costs, opportunities and risks against the desired performance of assets, to achieve the organisational objectives" [20]. Asset management is based on a set of four fundamental principles: assets provide value to an organization and its stakeholders; asset management is aligned to the organizational objectives; leadership and organizational culture are the basis for value creation; and, the goal of AM is to assure that assets will fulfil their required purpose [20]. In practice, the terms maintenance management and AM are often used interchangeably. However, the authors of this paper see maintenance management as a function of AM and also use $\mathrm{AM}$, as defined above, as the basis for the model presented in section 2.3.

\subsection{Lean Smart Maintenance Maturity Model}

LSM is a holistic management concept used to meet the highest reliability and availability requirements for critical plant components as well as minimize losses [21]. The smart perspective of the approach encompasses all those management aspects which drive the effectiveness part of LSM, with a focus on continuous improvement, a dynamic strategy adaption and a learning maintenance management. Output control replaces the cost-oriented input control. The lean perspective looks at the aspects relevant for an efficient asset and maintenance management system and focuses on the reduction on the input side of the management system, with resource conservation as a central pillar for a sustainable orientation. [22, 23]

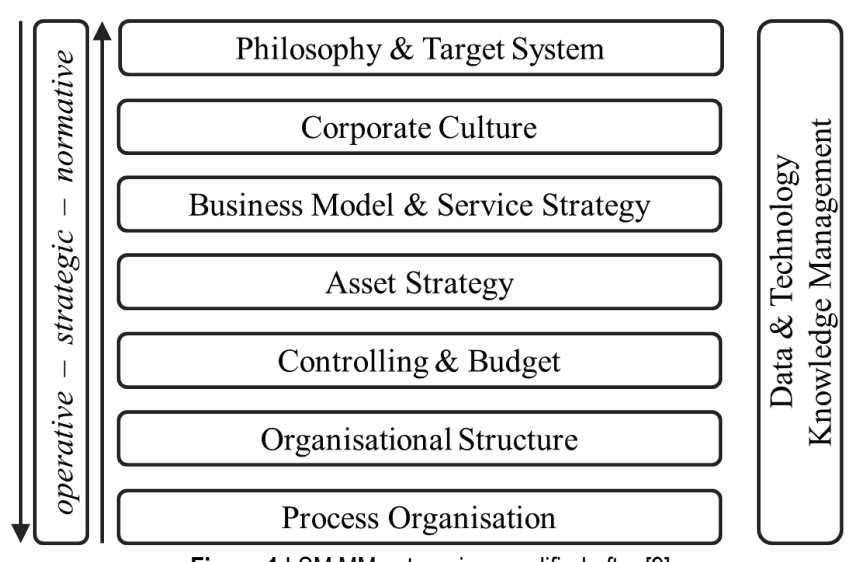

Figure 1 LSM MM categories, modified after [9]

Based on this LSM concept and selected aspects of I4.0, an LSM MM, was developed. MMs can be defined as artefacts with elements that are arranged in an evolutionary scale with measurable transitions from one level to another and which are used for benchmarking, self-assessment and continuous improvement $[7,22,24,25]$. The main LSM MM categories, spanning from normative to operative management, are represented in Fig. 1 [7]. The category 'Philosophy \& Target System' includes all those aspects that provide employees with the basic direction for their behaviour, like a vision, mission statement and the overall maintenance and asset goals.
Table $1 \mathrm{MM}$ categories and corresponding sub-categories

\begin{tabular}{|l|l|}
\hline \multicolumn{1}{|c|}{ Category } & \multicolumn{1}{c|}{ Sub Category } \\
Thilosophy \& & $\begin{array}{l}\text { Corporate Philosophy } \\
\text { Vision \& Mission; Target System }\end{array}$ \\
\hline $\begin{array}{l}\text { Corporate } \\
\text { Culture }\end{array}$ & $\begin{array}{l}\text { Culture; Employee Motivation; Leadership; Change } \\
\text { Management; Communication and Coordination; } \\
\text { Digital Competence }\end{array}$ \\
\hline $\begin{array}{l}\text { Business Model } \\
\text { \& Service } \\
\text { Strategy }\end{array}$ & $\begin{array}{l}\text { Maintenance Services/Stakeholder; } \\
\text { Context; Connection/Remote Services } \\
\text { Coordination }\end{array}$ \\
\hline Asset Strategy & $\begin{array}{l}\text { Maintenance Strategy; Life Cycle Management } \\
\text { Outsourcing Strategy; Spare Parts Management }\end{array}$ \\
\hline $\begin{array}{l}\text { Controlling \& } \\
\text { Budget }\end{array}$ & $\begin{array}{l}\text { Budgeting Process } \\
\text { Cost Allocation } \\
\text { Controlling System } \\
\text { Performance Indicators }\end{array}$ \\
\hline $\begin{array}{l}\text { Organizational } \\
\text { Structure }\end{array}$ & $\begin{array}{l}\text { Structuring; Workshops; Decentralization } \\
\text { Autonomous Maintenance; Integration into the } \\
\text { Organization; Optimization of the Structure }\end{array}$ \\
\hline $\begin{array}{l}\text { Process } \\
\text { Organization }\end{array}$ & $\begin{array}{l}\text { Process Management; Planning; Process Control; } \\
\text { Execution; Weak Pont Analysis; Process Efficiency; } \\
\text { Asset Monitoring; Use of Technology in Process } \\
\text { Organization }\end{array}$ \\
\hline $\begin{array}{l}\text { Knowledge } \\
\text { Management }\end{array}$ & $\begin{array}{l}\text { Qualification Management } \\
\text { Apprenticeship \& Trainings } \\
\text { Knowledge Coordination }\end{array}$ \\
\hline $\begin{array}{l}\text { General IT System; Data Storage/Transfer } \\
\text { Technology } \\
\text { Data Acquisition; Data Security/Access; Digital } \\
\text { Representation; Visualization/Analysis; Assistance } \\
\text { Systems/I4.0 Components; Data Integrity; Data } \\
\text { Quality }\end{array}$ \\
\hline
\end{tabular}

'Corporate Culture' takes a look at aspects around motivation, leadership, change management and communication. The category 'Business Model \& Service Strategy' considers new developments and new business models around asset and maintenance management. 'Asset Strategy' encompasses all aspects around maintenance strategy, maintenance prevention, outsourcing and spare parts management. The budgeting and controlling processes are concretized in 'Controlling \& Budget'. 'Organizational Structure' focuses on the formal division of job tasks, how they are grouped and coordinated, while 'Process Organization' encompasses planning, information, continuous improvement and weak-point-analysis processes. Planning incorporates internal coordination and scheduling of maintenance tasks. Two categories, 'Data \& Technology' and 'Knowledge Management' are treated as further dimensions that affect all maturity categories. The different categories have several sub-categories each, as represented in Tab. 1. [7] Each of these sub-categories includes a few items, or characteristics, which describe the sub-categories in further detail. For each of these items there is one or more interview questions designed to gather the information necessary to describe the organization's maturity. The MM architecture is based on the structure of the capability maturity model integration (CMMI), with its maturity levels from Incomplete to Optimizing [7, 26, 27]. However, it can be characterized as a hybrid MM, as it contains both characteristics of progression- (scaling of characteristics) and capability MMs. Furthermore, it can be described as a prescriptive MM, as it is used as the basis for organizational improvement $[7,24,28]$. Fig. 2 schematically depicts the 
logic behind the process of finding the maturity of the organization under investigation.

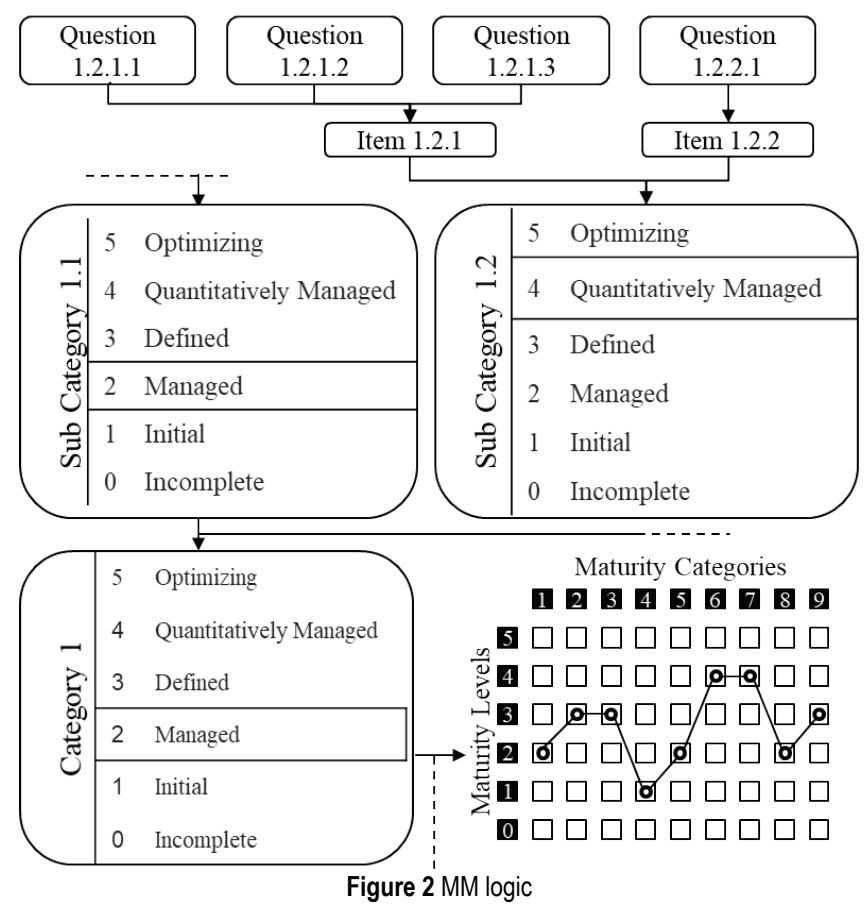

As visualized, the questions and their corresponding items lead to the determination of the maturities in the subcategories while the least mature sub-category defines the maturity of the corresponding category.

\section{METHODOLOGY}

This paper is set up as validation of the LSM MM with three different use cases. To ensure a scientifically founded methodology, the qualitative case study design after YIN was used. YIN proposed a 5-step model to perform such a study. The phases are as follows: Design, Prepare, Collect, Analyse, and Share the results [29]. Figure 3 shows the individual phases and their interactions with each other.

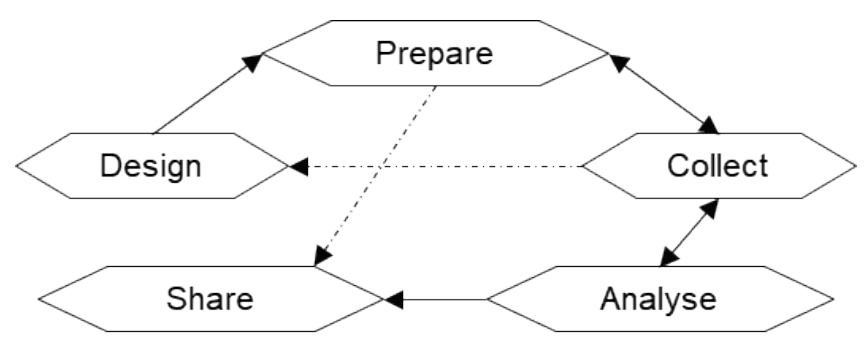

Figure 3 Iterative case study research process, modified after [29]

Case studies are answering research questions in the form of 'how' and 'why' and focus on modern problems or events. This is only possible if a few crucial components of this research design are considered. The underlying case study's question, which was stated in section 1 'Introduction', is the essential part with which we begin. The defined research question may not consider all necessary aspects of the case in sufficient detail; therefore, it may be necessary to provide a more precise research question, which can be achieved by introducing propositions. Propositions support the conducting of a case study, by consciously looking at different aspects of the case, in order to avoid misinterpretations through first results.

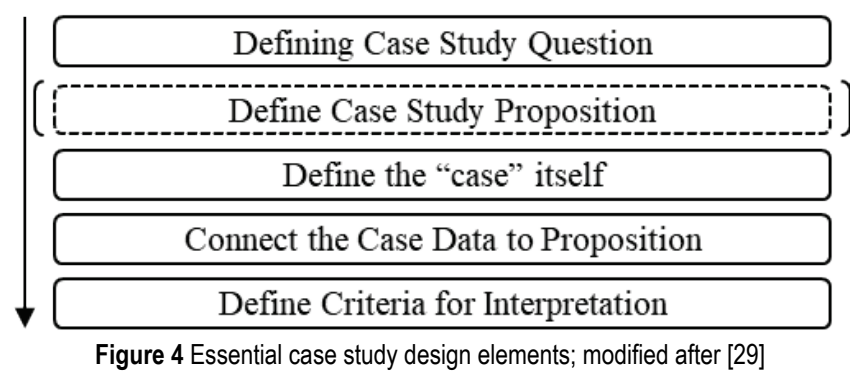

Nevertheless, it is also possible that a case study is not designed with the definition of propositions. Instead, it can be designed to serve a specific purpose, for example, validate a concept or method with several different cases, and also has to clarify the parameters or criteria of success, by which the success or failure of scientific work should be evaluated. The third phase is to define the 'case', which can vary in scope, e.g. small groups, programmes, and entire organisations. By specifying the target of observation, boundaries have to be set. These boundaries can be temporal, spatial or even more detailed, for example, a specific industry sector or size of companies, or even only projects during a certain time. 'Linking data to the proposition' is the fourth element which is concerned with analytic techniques as 'explanation building', 'logic models' or 'pattern matching'. The final step of the case study design phase is to define criteria of how to interpret the different findings. [29] Fig, 4 illustrates the detailed sequence of the design phase (Fig. 3), which was used as a guideline for this paper.

In the following chapter, the project data are defined, limitations are highlighted, and the structure of the analyses is represented.

\section{PROJECT DATA}

Based on the case study design research process, the performed assessments of three different projects have been analysed. The assessed company sites are located in Austria and represent production facilities from international companies. These assessments were chosen due to different production types, degree of a concatenation of production, size and structure of the organisations themselves. Due to compliance, the names of the companies were changed to Company A, B and C. For a better understanding of the companies, the different characteristics of each company will be highlighted. Company A is the largest company with about 1400 employees at the production site, followed by Company C and B with 600 and 480 employees respectively. The production types are classified into three different groups after Woodward [30]. The complexity of the production facilities starts from low technical complexity in group 1 up to high technical complexity in group 3. Company A 
corresponds to group 1 (small batch \& unit production), company B can be classified as group 3 member (continuous process production), and company $\mathrm{C}$ is part of group 2 (large batch \& mass production). As it is seen, due to the different types and complexity of production systems, the companies represent a broad spectrum of the producing industries, and therefore these projects were chosen to prove the generic applicability of the new LSM MM.

Each project intended an increase in efficiency and or effectivity of the maintenance department. Semi-structured interviews were performed with 125 employees, distributed among $\mathrm{A}, \mathrm{B}$ and $\mathrm{C}$, to generate a comprehensive view of the departments. Employees from all hierarchical levels were questioned. In order not to go beyond the scope of this publication, the following breakdown of the different levels only represents the complete distribution from all interviews. As it is seen in Fig. 5, the main focus of the interviews was on the operative level, to get a deep insight into the working behaviour and methods of each company, followed by interviews with the lower and middle management level which represent $43 \%$ of the employees interviewed. The focus of the project with company A was a Total Productive Maintenance (TPM) implementation and first steps towards a digitized maintenance organization. The project with company B had a special focus on communication within the company, especially communication between the functional units of production and maintenance. The third project additionally included basic assessment of production, planning \& control and quality assurance. Items around the new category 'Business Model \& Service Strategy' were not part of these assessments; therefore, a further discussion of this category is out of scope. Out of the interviews, it was possible to identify the status quo of each maintenance department with the already existing maintenance maturity model modified after Schroeder [5]. In general, the maturities of companies A and B can be described as very similar, while company $\mathrm{C}$ has a usually higher maturity in the different categories.

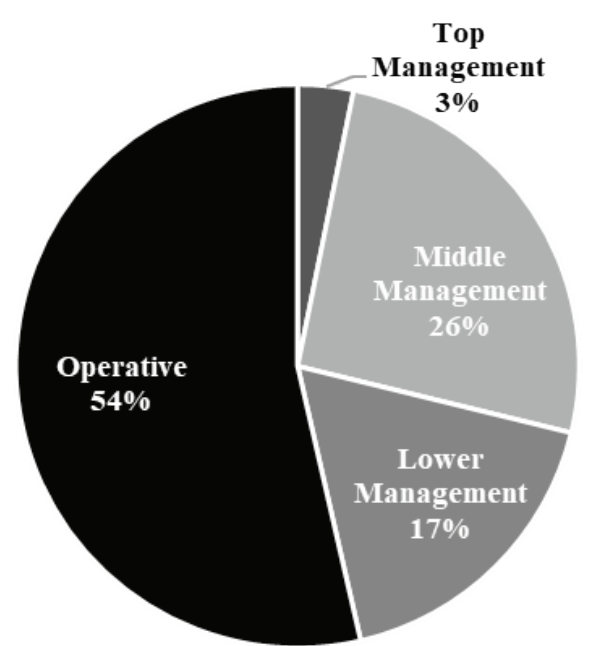

Figure 5 organisational breakdown by organisational hierarchy

The MM structure used in the different projects was slightly different in each case, which emphasises the need for the new, holistic and standardised LSM MM, which was proposed by Schmiedbauer et al. [7].

\section{RESULTS}

The different organisational setup leads to varying maturity levels for each one of the companies. In order to gain a better understanding of the structure and operation of these enterprises, the following three sections will explain each asset organisation in detail.

\subsection{Company A}

Company A represents the small-batch \& unit production type. As it is seen in Figure 6, Company A, as well as company B and C, had the same level of 'Philosophy \& Target System' (Level 2), which, in the case of company A, was attributable to the lack of understanding of the addedvalue generated by the maintenance department in terms of holistic asset management. A consistent target system was partially implemented, which resulted in varying control options for the different maintenance processes. The missing vision for the maintenance department, which in general should be derived from the company's vision, was the potential to enhance focus and understanding of maintenance as a value provider. On the other side, the higher maturity in 'Organisational Structure' was achieved due to the objectorientation of the maintenance organisation. The objectoriented contact persons of this level correlate directly with level three in 'Knowledge Management', where objectoriented professional development courses are a prerequisite. A closer look at the 'Corporate Culture' showed high potential in creating a structured communication format between shop-floor and management level. The affiliation of the employees with the company was identified as an enabler for the new communication channels.

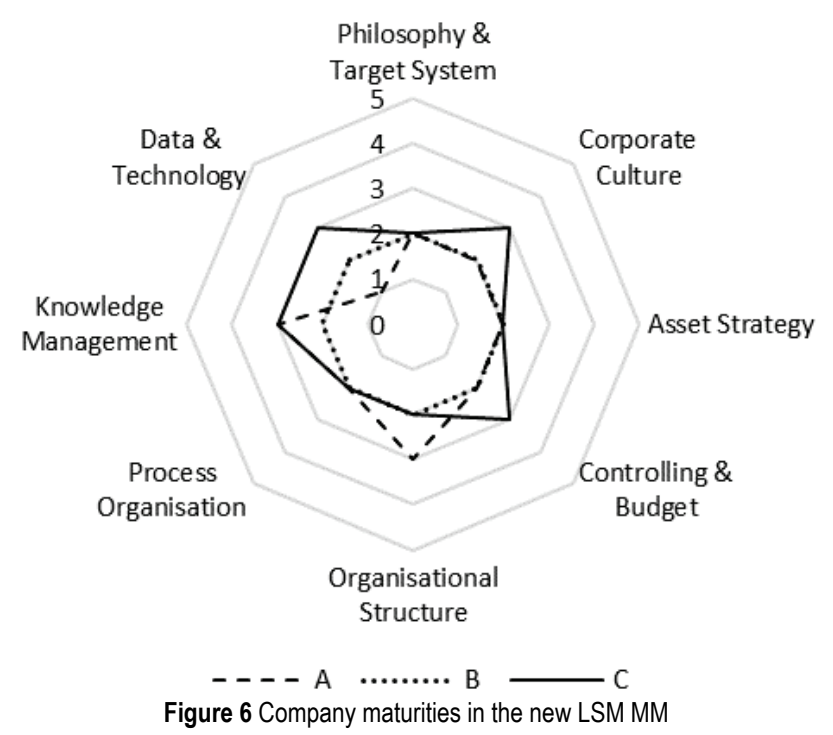

The 'Asset Strategy' category was rated with maturity level 2 of 5 . This was based mainly on the predominating preventive maintenance strategy, a spare parts warehouse 
that was complete regarding the inventory, but spread over the whole production site, as well as a not completely defined outsourcing process. Lastly, the category 'Data \& Technology' is explained. Company A had the lowest maturity of the three companies regarding data and technology application and standards. The company had no defined strategy regarding data management, which contains defined processes about data storage, handling, preprocessing, and so forth. There were several intersections between the different data systems (SCADA; ERP); therefore, the maturity in the category 'Data \& Technology' was 1 . With ongoing automation and digitalization, the authors anticipate a high potential for improvement in this category.

\subsection{Company B}

The case of company B indicates that a high degree of automation in production processes does not have to correlate with high maturity of asset management. Throughout all categories, only a level 2 maturity was reached. Starting from 'Philosophy \& Target System', the total asset and maintenance management was only seen as a necessary cost factor, not as a strategic function. The interviews and their unsystematic employee surveys showed that a high number of the workers were unsatisfied, which resulted in a rising fluctuation in this company when compared to the past. Besides, there was no systematic change management. However, a basic but non-transparent bonus scheme had been already implemented. As part of the category 'Asset Strategy', spare parts management software was already implemented, processes for spare parts were well-defined. Nonetheless, there were still unofficial storage sites in some areas. For maintenance prevention, basic processes were defined; however, maintenance was not optimally integrated into the procurement processes. As expected in the highly automated environment of company $\mathrm{B}$, there was a strong focus on preventive maintenance. In some cases, condition monitoring was possible, but usually not used due to a lacking qualification of employees. Maintenance strategies were mainly chosen based on the experience of the management and not by using a systematic approach. In outsourcing, long-term relationships with other companies were established and seen as a strategic factor, but there was a complete lack of a formal outsourcing process. In 'Controlling \& Budget' there was a strong focus on costoriented performance indicators. Aside from cost-oriented Key Performance Indicators (KPIs), the overall equipment effectiveness (OEE) was used, and there were a number of environmental KPIs, mainly due to compliance reasons. The budgeting process was well-defined, maintenance costs budgeted at the object level and budget deviations analyzed. The 'Organisational Structure' was strictly function oriented, first steps towards autonomous maintenance were taken. The 'Process Organisation' was characterized by non-digital ways of communication and basic capacity planning. There was no knowledge management system implemented; technical training was however available for the employees. Data security protocols were well established, some standard software used, yet many interfaces were problematic, which resulted in, for example, the necessity to export data from SAP and other systems and calculate KPIs in Excel.

\subsection{Company C}

Of the three cases described, company $\mathrm{C}$ has the overall highest maturity in the new LSM MM, with category maturities ranging from 2-3. It had a defined mission and vision for the whole production team, including maintenance, even though maintenance is not explicitly mentioned, meaning that the normative base for the target system is defined. The importance of the maintenance organization was recognized by the management and other employees, and maintenance organization optimization projects had already been carried out in the past. The corporate culture could be summarised by the statement brought forward by almost every employee during the interviews, namely, 'that they cannot really complain about their work.' This indicated a high loyalty towards the company as a whole, which was explained by the fact that the production at this site was almost independent of macroeconomic cycles, leading to secure jobs and for the region relatively high salaries. This, however, led to a low change readiness of the workers. Employee motivation was high and regularly surveyed, and a basic bonus scheme was implemented. The main reason for the low scoring in the category 'Asset Strategy' was the spare parts management. About $20 \%$ of the spare parts were mapped in SAP, and the spare parts management processes could be best described as semi-formalized. Spare parts are ordered based on the experience of the maintenance managers. Maintenance prevention was formalized; there was, however, improvement potential concerning life-cycle orientation. In this project, the maintenance strategies were dominated by reactive maintenance. Furthermore, a basic criticality assessment of different assets had already been carried out once, and maintenance strategies were defined for each asset. The company had an implemented controlling system, including a three-level Balanced Scorecard (BSC). Mostly at the shop-floor level, the performance indicator system was intermittent, some KPIs were available for production, but none for the maintenance workers. The whole KPI system was still very new, and deviations of KPIs not always analyzed and measures rarely derived. There was a well-implemented, static budgeting process and costs were allocated at the asset level and all necessary cost categories defined. The organizational structure could be described as very conservative; a strong functional job categorization and practically no autonomous maintenance was present. 'Process Organisation' was characterized by first attempts towards a digital maintenance ordering system. Usually, maintenance times were first recorded on paper and only entered into the system at the end of the week, and there was no structured weak point analysis. There was no structured knowledge management; however, a detailed qualification matrix and a comprehensive training program were available. Most processes around data were well defined; there were regular data quality checks and a responsible data manager. Parallel software solutions were in use, for example production planning in SAP and in Excel, which compromised the quality of the data and the basis for KPIs. 


\section{DISCUSSION AND OUTLOOK}

Ever-increasing complexity and volatility and the developments around I4.0 urge companies to use holistic thinking with respect to asset management. Maintenance departments have the potential to increase their effectiveness and efficiency. To reach higher efficiency and effectivity, the LSM philosophy and the LSM MM were developed. At the beginning of this paper, an introduction on the terms of I4.0, asset and maintenance management as well as in overview of the LSM philosophy and the LSM MM was given. It was followed by the methodological approach used as a basis for this scientific work. To answer the research question: 'Is the new LSM MM generic applicable?', three different reorganization projects were considered and analysed. These companies showed characteristics of different production type classifications (small batch-, continuous and mass production), different organizational structures, and varying employee number in the maintenance and production departments. Resulting from the transfer of the companyspecific data into the new LSM MM, it can be stated that company $\mathrm{A}$ and $\mathrm{B}$ have a similar, and company $\mathrm{C}$ a higher overall maturity. The authors have proven the generic applicability of the LSM MM. Next steps for further research are the application of the LSM MM in upcoming reorganization project and a more intensive investigation of the category 'Business \& Service Strategy'. Limitations of this work are that only the data from Austrian companies was analyzed and the category 'Business \& Service Strategy' has not been applied.

\section{Notice}

The paper will be presented at MOTSP 2020 International Conference Management of Technology - Step to Sustainable Production, which will take place from $30^{\text {th }}$ September $-2^{\text {nd }}$ October 2020 in Bol, island Brač (Croatia). The paper will not be published anywhere else.

\section{REFERENCES}

[1] Akdil, K. Y., Ustundag, A., \& Cevikcan, E. (2018). Maturity and Readiness Model for Industry 4.0 Strategy. In: Industry 4.0: Managing the Digital Transformation. Godalming: Springer-Verlag London Ltd, 61-94. https://doi.org/10.1007/978-3-319-57870-5_4

[2] Berghaus, S., Back, A., \& Kaltenrieder, B. (2016). Digital Maturity \& Transformation Report 2015.

[3] de Carolis, A., Macchi, M., Negri, E, \& Terzi, S. (2017). A Maturity Model for Assessing the Digital Readiness of Manufacturing Companies. In: Lödding, H., Riedel, R., Thoben, K-D., von Cieminski, G., Kiritsis, D., editors. Advances in Production Management Systems. The Path to Intelligent, Collaborative and Sustainable Manufacturing. Cham: Springer International Publishing, 13-20. https://doi.org/10.1007/978-3-319-66923-6_2

[4] Lee, J., Jun, S., Chang, T-W., \& Park, J. (2017). A Smartness Assessment Framework for Smart Factories Using Analytic Network Process. Sustainability, 9(5), 794. https://doi.org/10.3390/su9050794

[5] Schröder, W. (2010). Ganzheitliches Instandhaltungsmanagement: Aufbau, Ausgestaltung und Bewertung. Zugl.:
Leoben, Montanuniv., Diss., 2009. $1^{\text {st }}$ ed. Wiesbaden: Gabler Verlag / GWV Fachverlage GmbH Wiesbaden. https://doi.org/10.1007/978-3-8349-8481-4

[6] Schumacher, A., Erol, S., \& Sihn, W. (2016). A Maturity Model for Assessing Industry 4.0 Readiness and Maturity of Manufacturing Enterprises. Procedia CIRP 2016, 52, 161-166. https://doi.org/10.1016/j.procir.2016.07.040

[7] Schmiedbauer, O., Maier, H. T., \& Biedermann, H. (2020). Evolution of a Lean Smart Maintenance Maturity Model towards the new Age of Industry 4.0. Hannover Institutionelles Repositorium der Leibniz Universität Hannover.

[8] Evans, P. \& Annunziata, M. (2012). Industrial Internet: Pushing the boundaries of minds and machines. General Electric.

[9] Bauernhansl, T., ten Hompel, M., \& Vogel-Heuser, B. (eds.). (2014). Industrie 4.0 in Produktion, Automatisierung und Logistik: Anwendung, Technologien, Migration. Wiesbaden: Springer Vieweg. https://doi.org/10.1007/978-3-658-04682-8

[10] Bürger, T. \& Tragl, K. (2014). SPS-Automatisierung mit den Technologien der IT-Welt verbinden. In: Bauernhansl, T., ten Hompel, M., Vogel-Heuser, B., editors. Industrie 4.0 in Produktion, Automatisierung und Logistik: Anwendung, Technologien, Migration. Wiesbaden: Springer Vieweg, 559569. https://doi.org/10.1007/978-3-658-04682-8_28

[11] Davis, J., Edgar, T., Porter, J., Bernaden, J., \& Sarli, M. (2012). Smart manufacturing, manufacturing intelligence and demanddynamic performance. Computers \& Chemical Engineering, 47, 145-56. https://doi.org/10.1016/j.compchemeng.2012.06.037

[12] Wiesmüller, M. (2014). Industrie 4.0: surfing the wave? Elektrotech. Inftech, 131(7), 197. https://doi.org/10.1007/s00502-014-0217-x

[13] Alcácer, V. \& Cruz-Machado, V. (2019). Scanning the Industry 4.0: A Literature Review on Technologies for Manufacturing Systems. Engineering Science and Technology, 22(3), 899919. https://doi.org/10.1016/j.jestch.2019.01.006

[14] Park, S-C. (2018). The Fourth Industrial Revolution and implications for innovative cluster policies. AI \& Soc, 33(3), 433-445. https://doi.org/10.1007/s00146-017-0777-5

[15] Evans, D. (2012). The Internet of Everything: How More Relevant and Valuable Connections Will Change the World.

[16] Miraz, M. H., Ali, M., Excell, P. S., \& Picking, R. (2015). A review on Internet of Things (IoT), Internet of Everything (IoE) and Internet of Nano Things (IoNT). In: 2015 Internet Technologies and Applications (ITA), IEEE, 219-224. https://doi.org/10.1109/ITechA.2015.7317398

[17] Perales, D. P., Valero, F. A., \& García, A. B. (2018). Industry 4.0: A Classification Scheme. In: Viles, E., Ormazábal, M., Lleó, A., editors. Closing the Gap between Practice and Research in Industrial Engineering. Cham: Springer International Publishing, 343-350.

[18] DIN e.V. (2015). DIN EN 13306:2018-02 - Maintenance Maintenance terminology; Trilingual version / Begriffe der Instandhaltung; Dreisprachige Fassung (Deutsch, Englisch, Französisch), DIN-Normenausschuss Technische Grundlagen (NATG)

[19] Amadi-Echendu, J. E., Willett, R., Brown, K., Hope, T., Lee, J., Mathew, J. et al. (2010). What is Engineering Asset Management? In: Amadi-Echendu, J. E., Brown, K., Willett, R., Mathew J., editors. Definitions, Concepts and Scope of Engineering Asset Management. London: Springer London, 316. https://doi.org/10.1007/978-1-84996-178-3_1

[20] Asset management - Overview, principles and terminology (55000). Switzerland, 2014

[21] Biedermann H. (2016). Lean Smart Maintenance Wertschöpfende, lernorientierte und ressourceneffiziente 
Instandhaltung. In: Biedermann $\mathrm{H}$, editor. Lean smart maintenance: Konzepte, Instrumente und Anwendungen für eine effiziente und intelligente Instandhaltung: 30. Instandhaltungsforum. Köln: TÜV Media, 19-29.

[22] Biedermann, H. \& Kinz, A. (2019). Lean Smart Maintenance Value Adding, Flexible, and Intelligent Asset Management. BHM Berg- und Hüttenmännische Monatshefte. https://doi.org/10.1007/s00501-018-0805-x

[23] Kinz, A., Bernerstätter, R., \& Biedermann, H. (2016). Lean Smart Maintenance - Efficient and Effective Asset Management for Smart Factories. In: Proceedings of the $8^{\text {th }}$ International Scientific Conference Management of Technology - Step to Sustainable Production, Porec.

[24] Caralli, R. (2012). Discerning the Intent of Maturity Models from Characterizations of Security Posture; Available from: https://resources.sei.cmu.edu/asset_files/WhitePaper/2012_01 9 001 58924.pdf.

[25] Mettler, T., Rohner, P., \& Winter, R. (2010). Towards a Classification of Maturity Models in Information Systems. In: de Marco, M., Braccini, A. M., Cabiddu, F., editors. Management of the interconnected world: ItAIS, the Italian Association for Information Systems. Heidelberg: SpringerVerlag Berlin Heidelberg, 333-340. https://doi.org/10.1007/978-3-7908-2404-9_39

[26] CMMI Institute. How is CMMI V2.0 different from V1.3? Available from: https://cmmiinstitute.zendesk.com/hc/enus/articles/360000175667-How-is-CMMI-V2-0-differentfrom-V1-3-.

[27] CMMI Institute. CMMI® for Development, Version 1.3 CMMI-DEV, V1.3 2010.

[28] de Bruin, T., et al. (2005). Understanding the Main Phases of Developing a Maturity Assessment Model (https://pdfs.semanticscholar.org/c00f/91faf37a75823a5 baca7415a5123ac4010f8.pdf)

[29] Yin, R. K. \& Campbell, D. T. (2018). Case study research and applications: Design and methods. Thousand Oaks California: SAGE Publications Inc.

[30] Woodward, J. (1994). Industrial organization: Theory and practice. $2^{\text {nd }}$ ed. Oxford: Oxford Univ. Press.

\section{Authors' contacts:}

Dipl.-Ing. Hans Thomas Maier, BSc

(Corresponding author)

Chair of Economic- and Business Management,

Department Economic and Business Management,

Montanuniversitaet Leoben,

Peter Tunner Straße 25-27, 8700 Leoben, Austria

+43 3842402 6018, hans.maier@unileoben.ac.at

ORCID: https://orcid.org/0000-0001-5714-3959

Dipl.-Ing. Oliver Schmiedbauer, BSc

Chair of Economic- and Business Management, Department Economic and Business Management, Montanuniversitaet Leoben,

Peter Tunner Straße 25-27, 8700 Leoben, Austria

+43 38424026005 , oliver.schmiedbauer@unileoben.ac.at

ORCID: https://orcid.org/0000-0003-0051-9614

O. Univ.-Prof. Dipl.-Ing. Dr. mont. Hubert Biedermann

Chair of Economic- and Business Management,

Department Economic and Business Management,

Montanuniversitaet Leoben,

Peter Tunner Straße 25-27, 8700 Leoben, Austria

+43 38424026000 , hubert.biedermann@unileoben.ac.at

ORCID: https://orcid.org/0000-0003-4678-4392 